\title{
Milk yield and estrous behavior during eight consecutive estruses in Holstein cows fed standardized or high energy diets and grouped according to live weight changes in early lactation
}

\author{
C. Gaillard, ${ }^{* 1}$ H. Barbu,† M. T. Sørensen, ${ }^{*}$ J. Sehested, ${ }^{*}$ H. Callesen, ${ }^{*}$ and M. Vestergaard ${ }^{*}$ \\ *Department of Animal Science, Aarhus University, 8830 Tjele, Denmark \\ †Dijon Sup Agro, 21079 Dijon Cedex, France
}

\begin{abstract}
Cows managed for extended lactation go through several estruses before rebreeding. The aims of this study were (1) to quantify the effect of the first 8 estruses after calving on milk yield, milking frequency, and estrous behavioral activity, and (2) to determine the effects of early lactation live weight gain (LWG) as an indication of energy balance on milk yield, plasma insulin-like growth factor 1 (IGF-1) concentration, estrous behavioral activity, interval from calving to first estrus, between-estrus intervals, and pregnancy risk. Milk yield, live weight, and estrous behavioral activity were measured daily in 62 Holstein cows, 17 primiparous and 45 multiparous, managed for an 18-mo calving interval. Blood plasma obtained at wk 3, 5, 12, and 24 after calving was analyzed for IGF-1. Estrus was detected by use of milk progesterone profiles combined with visual observations (i.e., mounting behavior and other). The cows were divided into 2 groups: the cows having a negative LWG in each of the first 5 wk postpartum and the cows having a positive LWG in at least 1 of the first 5 wk after calving. The results indicate a similar decrease of $0.56 \mathrm{~kg}$ of milk per day of estrus during each of the 8 consecutive estruses. The activity level was $17 \pm 1$ movements per hour higher during the 8 estruses compared with the basic activity level. More cows expressed mounting behavior at estrus 8 than at estrus 2 (63.3 and $45.9 \%$, respectively). The negative LWG cows had lower IGF-1 and higher milk production than the positive LWG cows. Both LWG groups had similar interval from calving to first estrus, on average 55 d. To conclude, the decrease in milk yield during estrus is marginal and similar in consecutive estruses. Moreover, estrous behavior is more highly expressed in the later estruses compared with the earlier estruses. Reproductive parameters (frequency of mounting, pregnancy risk, interval to first estrus, and between-
\end{abstract}

Received June 28, 2015.

Accepted December 8, 2015.

${ }^{1}$ Corresponding author: charlotte.gaillard@anis.au.dk estrus intervals) were not influenced by the live weight change during early lactation.

Key words: extended lactation, estrus, pregnancy risk, energy balance

\section{INTRODUCTION}

High-yielding dairy cows have been selected over generations for increased milk yield, but this is associated with a decrease in reproductive performance (Gilmore et al., 2011). This decrease is mainly due to the negative energy balance (EB) associated with high yields in early lactation (Walsh et al., 2011) and the relationship between body lipid reserves and the reproductive cycle (Friggens, 2003). With an 18-mo calving interval, as compared with a traditional 12-mo interval, rebreeding is postponed (Sorensen et al., 2008) to take place during a period in which most if not all cows are in a positive EB. Indeed, the EB is negative in early lactation (Lucy, 2001), but it returns to positive starting around 6 wk after calving (Butler et al., 1981; Gilmore et al., 2011); therefore, the first ovulations typically occur while the high-yielding cow is still in negative EB. Postponing rebreeding to later estruses seems to be a good management option in some situations (Sorensen and Knight, 2002); however, it will also result in more consecutive estruses, which might have a negative effect on milk production and will likely increase mounting activity. Increased activity and expression of mounting behavior during estrus might, however, have a positive influence on the ease of estrus detection (Nielsen et al., 2010). Nevertheless, increased activity could also negatively affect short-term milk production (Steensels et al., 2012). It has been shown that the milk production decreases, on average, $2.25 \mathrm{~kg}$ during the day of estrus with a traditional 12-mo calving interval (Schofield et al., 1991). A cow is in estrus when it is sexually receptive; usually this occurs every $21 \mathrm{~d}$ (range $=18-24 \mathrm{~d}$ ) and the estrus lasts for some hours $(14.1 \pm 4.5 \mathrm{~h}$ in Kerbrat and Disenhaus, 2004). This period was previously detected by observing specific mounting behavior (the cow stands still while mounted 
by another cow), but these days fewer cows are expressing mounting behavior (Kerbrat and Disenhaus, 2004). Measurements of milk progesterone can be used (Kerbrat and Disenhaus, 2004), associated with visual observations (i.e., chin resting, color and consistency of the mucus in the vulva; Esslemont et al., 1980; Foote, 1975), and measurements of activity (i.e., pedometers, collars; Hurnik et al., 1975) to precisely detect the day of estrus (Kerbrat and Disenhaus, 2004). The type of housing affects the number of cows expressing estrus. Indeed, more cows housed in stanchion barns expressed mounting than the cows housed in freestalls or pasture when driven twice daily to an observation area for 30 min (De Silva et al. 1981), and more mountings were observed on dirt than on concrete floors (Britt et al. 1986). A decline in estrous behavior expression is often associated with a decrease in reproductive performance and an increase in milk production (Spalding et al., 1975). Spicer et al. (1990) showed that cows expressing estrous behavior during the first and second estrous cycle, as detected by blood progesterone levels, had less negative EB than cows that did not express estrous behavior. Finally, IGF-1 has been identified as a mediator of EB-related effects on luteal function as it stimulates progesterone production (McArdle and Holtore, 1989).

We intended to quantify the decrease in milk production due to estrus and the mounting behavior over several consecutive estruses in cows managed for extended lactation (18-mo calving interval) in a loose housing system with milking robots. Thus, the objectives of the present study were to determine (1) the effect of consecutive estruses on milk yield, milking frequency, and estrus-related activity in dairy cows during extended lactation, and (2) the effect of live weight changes in early lactation on estrous behavioral activity, return to estrus, pregnancy risk, and plasma IGF-1 of cows in extended lactation.

\section{MATERIALS AND METHODS}

\section{Animals, Housing, and Feeding Strategies}

The experiment was carried out at the Danish Cattle Research Centre at Aarhus University, Foulum. It involved 62 Holstein cows, 17 primiparous and 45 multiparous, managed for an 18-mo calving interval. The number of cows was optimized for the measurement of production parameters of this feeding trial. All the cows were housed in one group pen on slatted floor with freestalls equipped with mattresses and sawdust bedding. The cows had access to water and an automatic milking system (AMS; DeLaval AB, Tumba, Sweden) and were voluntarily milked (mean $\pm \mathrm{SD}$ ) $2.77 \pm 0.18$ times per day during the period studied.
The cows were fed according to 1 of 2 strategies using 2 partially mixed rations, one with a high energy density $\left(\mathrm{HD} ; 7.81 \mathrm{MJ}\right.$ of $\mathrm{NE}_{\mathrm{L}} / \mathrm{kg}$ of $\left.\mathrm{DM}\right)$ and 50:50 forage-to-concentrate ratio; and one with a lower standardized energy density (LD; control diet, 7.49 MJ of $\mathrm{NE}_{\mathrm{L}} / \mathrm{kg}$ of $\mathrm{DM}$ ) and 60:40 forage-to-concentrate ratio, but still sufficient to meet the daily energy demands of a high-yielding lactating cow. Half of the cows were fed ad libitum the LD diet during the entire lactation (control strategy LD-LD, with 9 primiparous and 22 multiparous cows). The other half of the cows was fed the HD diet until they reached at least 42 DIM and a live weight gain $(\mathbf{L W G}) \geq 0 \mathrm{~kg} / \mathrm{d}$ based on a 5 -d live weight $(\mathbf{L W})$ average, and were then shifted to the LD diet (strategy HD-LD, with 8 primiparous and 23 multiparous cows). Insemination was initiated at first estrus after 220 DIM (e.g., at estrus $7.8 \pm 1.4$ d postpartum). The herd-average milk production for a 305-d lactation period was around 11,000 $\mathrm{kg}$ in 2014 .

\section{Measurements and Calculations}

Estrus Detection, Behavior, and Determination of the Day of Estrus. Estruses were detected and recorded for each cow until estrus number 8 . The day of estrus was defined based on milk progesterone profiles in combination with the visual observations. Progesterone $(\mathrm{ng} / \mathrm{mL})$ was automatically measured in individual cow milk, based on an immunoassay in the Herd Navigator (Lattec I/S, Hillerød, Denmark) system connected to the AMS. Visual observations [mounting or being mounted (i.e., estrous behavior), vulva swollen red, mucus discharge (i.e., viscous, clear elastic strands of mucus hanging from the vulva), presence of blood in the genital area] were recorded by the farm personnel (2 experienced persons) daily for the cows at $21 \pm$ $3 \mathrm{~d}$ after the latest estrus and for those having high activity. The activity of the cows was recorded by a collar activity meter system (DelPro, DeLaval, Tumba, Sweden) mounted around the neck of each cow. The collar recorded the activity of each animal continuously and it was then expressed as number of movements per hour. The activity at the day of estrus was compared with the activity at $\mathrm{d} 5$ relative to the day of estrus. To determine the day of estrus, the following procedure was followed. First, the period in which an estrus could occur was defined by a low level of progesterone $(<3 \mathrm{ng} / \mathrm{mL}$; Lamming and Bulman, 1976). Within this period, the day of estrus was defined based on the visual observations in the following anticipated order of importance: (1) the day where the cow is mounting another cow or being mounted itself. If these observations were not recorded during the estrus period, but (2) "swollen red, mucus discharge" was recorded, then 
Table 1. Visual criteria for definition of day of estrus

\begin{tabular}{ll}
\hline Visual observation & Defined day of estrus relative to day of observation \\
\hline Mounting, mounted & Day of observation \\
Vulva swollen red, mucus discharge & Day of observation \\
Presence of blood in the genital area & Day 2 before the day of observation \\
\hline
\end{tabular}

this day was defined as the day of estrus. Finally, if neither (1) or (2) were recorded but (3) the presence of blood in the genital area was observed, then the day of estrus was defined as $2 \mathrm{~d}$ before this blood was observed (Table 1 ). One of these 3 criteria were recorded for each estrus period.

Insemination Recordings and Pregnancy Risk. The result of insemination (pregnancy or not) and the number of inseminations per pregnancy were recorded throughout the lactation. Pregnancy was detected by high level of progesterone for at least $30 \mathrm{~d}$ after insemination, and confirmed by rectal palpation. The average number of inseminations per pregnancy and average pregnancy risk after first and second inseminations were calculated.

$\boldsymbol{L} W$ and $\boldsymbol{L W G}$ Calculation. Live weight was recorded (Danvaegt, Hinnerup, Denmark) at each milking in the AMS. Weight recordings (10 times per second) were cleaned up, following the procedure described in Bossen and Weisbjerg (2009), and a daily average was calculated. To attenuate daily variations, the Wilmink model (Wilmink, 1987; equation [1]) was used to fit the daily individual LW measurements:

$$
\mathrm{LW}=\mathrm{a}+\mathrm{b} \times \mathrm{DIM}+\mathrm{c} \times \exp (-0.05 \times \mathrm{DIM}),[1]
$$

where LW is in kilograms; the factor -0.05 is the average time from calving at LW nadir ( $50 \mathrm{~d})$; $a$ is the level of LW; $b$ is the increase of LW after LW nadir; and $c$ is the decrease of LW toward the LW nadir. The parameters $\mathrm{a}, \mathrm{b}$, and $\mathrm{c}$ were calculated for each cow by linear regression ( $\mathrm{lm}$ function in $\mathrm{R}$ ). The equation for $\mathrm{LWG}$ [2] was the derivative of the LW equation for individual cows at each 7 DIM, representing the average weekly LWG:

$$
\mathrm{LWG}=\mathrm{b}-0.05 \times \mathrm{c} \times \exp (-0.05 \times \mathrm{DIM}) .
$$

Average weekly LWG was then used as an indicator of energy balance. Based on their weekly LWG, cows were divided into 2 groups. One group comprised the cows having a negative LWG in each week during the first 5 wk after calving (NLWG) and the other group comprised the cows having a positive LWG in at least 1 of the first 5 wk after calving (PLWG). The characteristics and mean LWG of these groups, as well as the distribution of PLWG and NLWG cows on the feeding strategies, are presented in Table 2.

Milk Yield and Milking Frequency. Milk yield was recorded by the AMS at each milking to calculate a daily yield for each cow. The data set used in the present study contains the daily yield $(\mathrm{kg} / \mathrm{d})$ for the day of estrus and baseline yield, defined as the average daily yield of $\mathrm{d}-6,-5$, and -4 relative to the day of estrus, expressing milk yield in the nonestrus period. Average of the daily milk yield was also calculated for wk 3, 5, 12, and 24. Milking frequency was based on individual cow visits to the AMS per day. The cows had free access to the AMS, but if the last visit occurred within $5 \mathrm{~h}$ the cows were denied access. If the cow spent $15 \mathrm{~h}$ not visiting the AMS, it was manually picked up and lead to the AMS.

Blood Samples. Blood was sampled during wk 3, 5, 12 , and 24 after calving from the tail vessel on Thursday mornings between 1000 and $1200 \mathrm{~h}$. Plasma was harvested and kept frozen at $-20^{\circ} \mathrm{C}$ until analyzed for

Table 2. Characteristics of the live weight gain (LWG) groups $^{1}$

\begin{tabular}{lcc}
\hline Item $^{2}$ & NLWG & PLWG \\
\hline Total of cows & 29 & 33 \\
Number of primiparous & 8 & 9 \\
Number of HD-LD cows & 13 & 18 \\
Number of LD-LD cows & 16 & 15 \\
Average LWG when wk $\leq 5, \mathrm{~kg} / \mathrm{d} \pm$ SEM & $-0.66 \pm 0.07$ & $0.15 \pm 0.07$ \\
Average LWG when wk $>5, \mathrm{~kg} / \mathrm{d} \pm$ SEM & $0.28 \pm 0.03$ & $0.33 \pm 0.03$ \\
\hline
\end{tabular}

${ }^{1}$ PLWG $=$ cows having a positive LWG in 1 of the first $5 \mathrm{wk}$ after calving; NLWG $=$ cows having a negative LWG in each of the first 5 wk after calving.

${ }^{2} \mathrm{HD}-\mathrm{LD}=$ cows fed 2 partially mixed rations, a 50:50 forage-to-concentrate diet during the mobilization period and the control diet after (60:40 forage-to-concentrate); LD-LD = cows fed the same partially mixed ration, a 60:40 forage-to-concentrate diet during all the lactation. 
IGF-1 using a noncompetitive time-resolved immunofluorometric assay of the sandwich type, as described by Frystyk et al. (1995).

\section{Statistical Analysis}

Linear Mixed-Effects Models. Three different linear mixed-effects models were used as 3 different time frames (DIM, days relative to the day of estrus, or weekly average at wk $3,5,12$, and 24 ) were studied. Model [1] tests the effects of parity, estrus number, feeding strategy, and event (estrus, nonestrus) on daily milk yield, daily activity, or daily milking frequency. Model [2] tests the effect of days from estrus, parity, and feeding strategy on milking frequency and daily milk yield around estrus. Model [3] tests the effects of parity, feeding strategy, and LWG group on daily milk yield, IGF-1, LWG, interval from calving to first estrus, intervals between estruses, DIM at first insemination, and number of estruses at first insemination.

$$
\begin{gathered}
\text { Model [1]: } \mathrm{Y}_{\mathrm{ijklm}}=\mu+\mathrm{E}_{\mathrm{i}} \times \mathrm{P}_{\mathrm{j}} \times \mathrm{S}_{\mathrm{k}} \\
\times \mathrm{N}_{\mathrm{m}}+\mathrm{C}_{\mathrm{jkl}}+\varepsilon_{\mathrm{ijklm}},
\end{gathered}
$$

$\operatorname{model}[2]: \mathrm{Y}_{\mathrm{ijkl}}=\mu+\mathrm{D}_{\mathrm{i}} \times \mathrm{P}_{\mathrm{j}} \times \mathrm{S}_{\mathrm{k}}+\mathrm{C}_{\mathrm{jkl}}+\varepsilon_{\mathrm{ijkl}}$, and

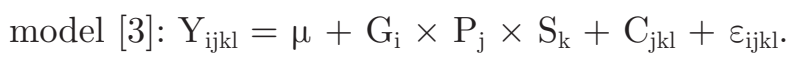

In model [1], Y is the variable studied (daily milk yield, daily activity or daily milking frequency), $\mu$ is the overall mean, $\mathrm{E}$ is the effects of the ith estrus event (estrus, nonestrus), $\mathrm{P}$ is the effect of the jth parity (primiparous, multiparous), $\mathrm{S}$ is the effect of the kth feeding strategy (LD-LD or HD-LD), $\mathrm{N}$ is the effect of the mth estrus number ( $m=1$ to 8$)$, with the respective 2 - and 3 -factor interactions, $\mathrm{C}_{\mathrm{jkl}}$ is the random effect of the lth cow within $\mathrm{j}$ parity and $\mathrm{k}$ strategy, and $\varepsilon_{\mathrm{ijklm}}$ is the random residual error. The feeding strategy, and its interactions, was excluded from the final model after it was tested not to have effect on the variables analyzed.

In model [2], $\mathrm{Y}$ is the variable studied (daily milking frequency or daily milk yield), $\mu$ is the overall mean, D is the effects of the ith days from estrus ( -6 to 6 ), $\mathrm{P}$ is the effect of the jth parity (primiparous, multiparous), $\mathrm{S}$ is the effect of the kth feeding strategy (LD-LD or HD-LD), with the respective 2-factor interactions, $\mathrm{C}_{\mathrm{jkl}}$ is the random effect of the lth cow within $\mathrm{j}$ parity from estrus and $\mathrm{k}$ strategy, and $\varepsilon_{\mathrm{ijkl}}$ is the random residual error. The feeding strategy, and its interactions, was excluded from the final model after it was tested not to have effect on the variables analyzed.

In model [3], Y is the variable studied (average daily milk yield at wk $3,6,12$, and 24 ; IGF-1, LWG, interval from calving to first estrus, intervals between estruses, DIM at first insemination, and number of estruses at first insemination), $\mu$ is the overall mean, $G$ is the effects of the ith LWG group (NLWG or PLWG), $\mathrm{P}$ is the effect of the jth parity (primiparous, multiparous), $\mathrm{S}$ is the effect of the kth feeding strategy (LD-LD or HD-LD), with the respective 2- and 3-factor interactions, $\mathrm{C}_{\mathrm{jk}}$ is the random effect of the lth cow within $\mathrm{j}$ parity and $\mathrm{k}$ feeding strategy, and $\varepsilon_{\mathrm{ijkl}}$ is the random residual error. For the IGF-1 analysis, the week factor was added to the model as well as its 2- and 3-factor interactions.

With R version 3.0.0 (R Development Core Team, 2014), the lme function from the nlme package (Pinheiro et al., 2015) was used to fit the models. This generic function fits a linear mixed-effects model in the formulation described by Laird and Ware (1982). The correlation between repeated measurements within each cow was calculated with the corAR1 function, a temporal autocorrelation structure of order 1 that uses the order of the observations in the data set as covariate (Pinheiro and Bates, 2000).

Chi-Square Tests and Pearson Correlations. The effects of LWG group, feeding strategy, parity, and estrus number on the number of cows exhibiting estrus (mounting or being mounted), pregnancy risks, and number of inseminations per pregnancy were tested using a chi-square test on $\mathrm{R}$ software (chisq.test function; Agresti, 2007). In addition, the chi-square test was used to compare the length of intervals between estrus 1 to 2 and estrus 7 to 8 . To do so, the length of intervals was categorized as regular (18-26 d) or irregular (31-57 d). Correlations between daily milk yield and milking frequency, between LWG and plasma IGF-1, and between estrus number and number of cows expressing mounting behavior were quantified by a simple Pearson correlation with $\mathrm{R}$ software (cor.test function; Hollander and Wolfe, 1973).

\section{RESULTS}

\section{Effect of Estrus on Milk Yield and Milking Frequency}

The feeding strategy was found not to have an effect on the daily milk yield $(P=0.92)$ and milking frequency $(P=0.55)$. Daily milk yield was $0.56 \pm 0.19 \mathrm{~kg}$ lower $(P<0.001)$ on the day of estrus compared with the average of $\mathrm{d}-4,-5$, and -6 relative to estrus (Figure 1). This difference in milk yield was not affected by parity $(P=0.51)$ or estrus number $(P=0.25)$. The milking frequency was positively correlated with the daily milk yield $(\mathrm{r}=0.49, P<0.001)$. Even so, no difference in milking frequency was noted between the day of estrus and the $\mathrm{d}-6,-5$, and -4 relative to 


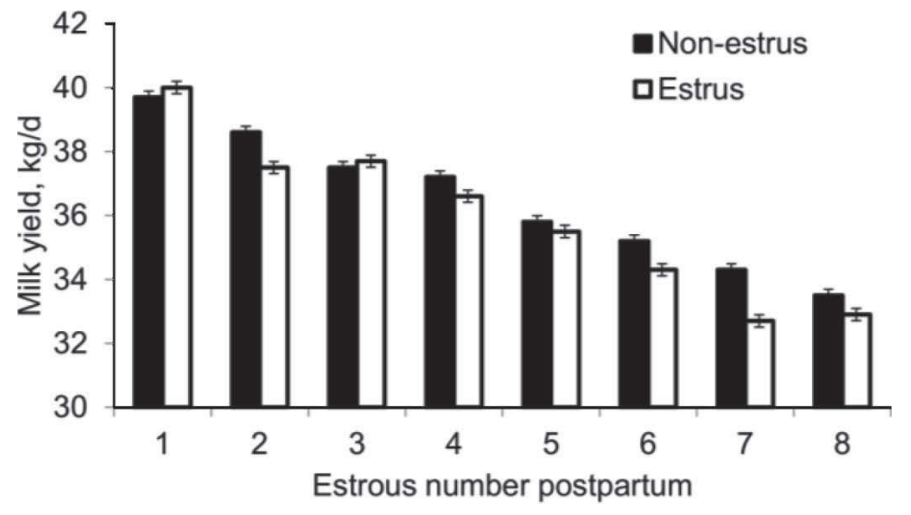

Figure 1. Milk yield (kg/d; mean \pm SEM) during estrus and nonestrus ( -6 to $-4 \mathrm{~d}$ relative to estrus).

estrus ( $P=0.23$, average $2.7 \pm 0.09$ milking per day). An increase in milking frequency was observed at $\mathrm{d}$ $-3,-2$, and -1 relative to estrus $(P<0.001)$, as well as an increase in milk yield at $\mathrm{d}-2$ relative to estrus compared with $\mathrm{d}-3$ relative to estrus (36.8 vs $36.1 \pm$ $0.02 \mathrm{~kg}, P=0.03$; Figure 2).

\section{Variation in Daily Activity During Estrus}

The feeding strategy was tested not to have effect on the daily activity $(P=0.31)$. Activity was generally higher during the 3 first estruses and then decreased until estrus $8(P<0.001$; Figure 3$)$. Activity was, on average, $17 \pm 1$ movements per hour higher during estrus compared with $5 \mathrm{~d}$ before estrus $(P<0.001)$. There was an interaction between parity and estrus number, indicating that during nonestrus the multiparous cows were more active than the primiparous cows from estrus number 2 to 6 , whereas during estrus the primiparous were more active than the multiparous in

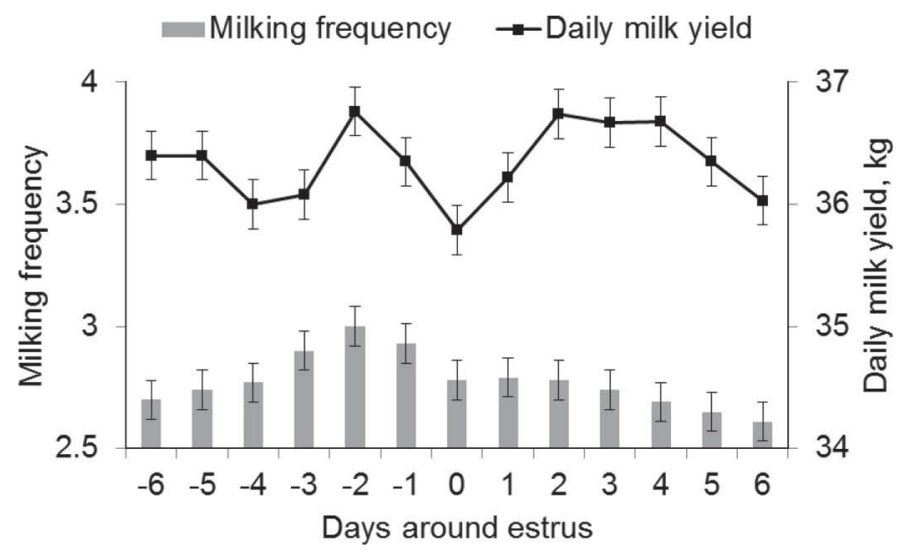

Figure 2. Daily milk yield $(\mathrm{kg} / \mathrm{d}$; mean \pm SEM) and daily milking frequency around estrus $(\mathrm{d}=0)$.

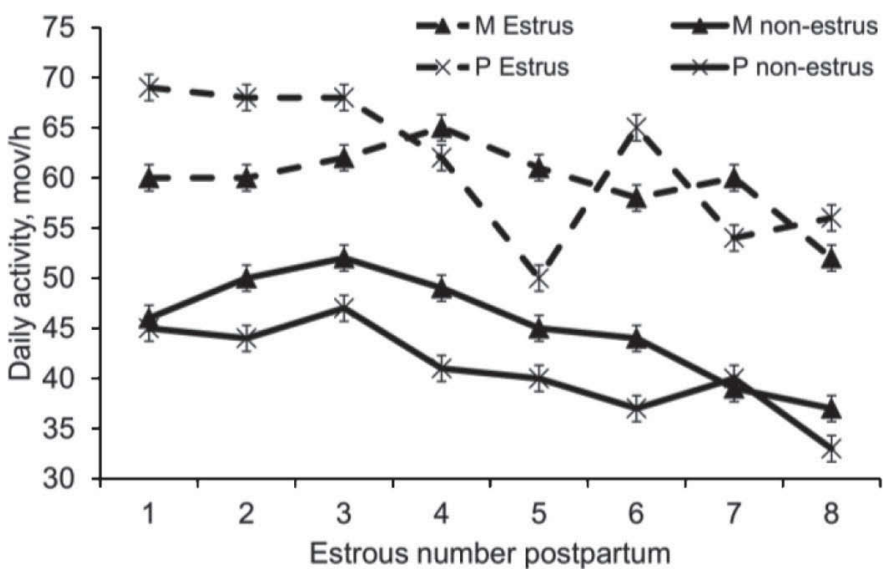

Figure 3. Activity [number of movements per hour (mov/h); mean $\pm \mathrm{SEM}]$ during estrus and nonestrus for multiparous (M) and primiparous $(\mathrm{P})$ cows.

estruses $1,2,3$, and $6(P<0.001)$ and less active than the multiparous in estruses 5 and $7(P<0.001)$. A positive correlation was noted between estrus number and the number of cows expressing mounting behavior $(\mathrm{r}=0.79, P=0.02)$ (Figure 4$)$. More cows tended to express mounting behavior at estrus 8 than 2 (63.3 vs. 45. $9 \%, P=0.06)$.

\section{Relationships Between LWG Grouping and IGF-1, Milk Yield, Estrous Behavior, and Estrus Intervals}

LWG Groups. During the first 5 wk after parturition LWG was $-0.66 \pm 0.07 \mathrm{~kg} / \mathrm{d}$ for the NLWG group and $0.15 \pm 0.07 \mathrm{~kg} / \mathrm{d}$ for the PLWG group $(P<0.001)$. During the period from 6 to 24 wk after parturition, the LWG was $0.28 \pm 0.03 \mathrm{~kg} / \mathrm{d}$ for NLWG and $0.33 \pm$ $0.03 \mathrm{~kg} / \mathrm{d}$ for PLWG $(P=0.22$; Figure 5$)$. Parity and feeding strategy had no effect on the LWG $(P=0.78$ and $P=0.98$, respectively). There was no effect of LWG groups or feeding strategy on the LW at calving,

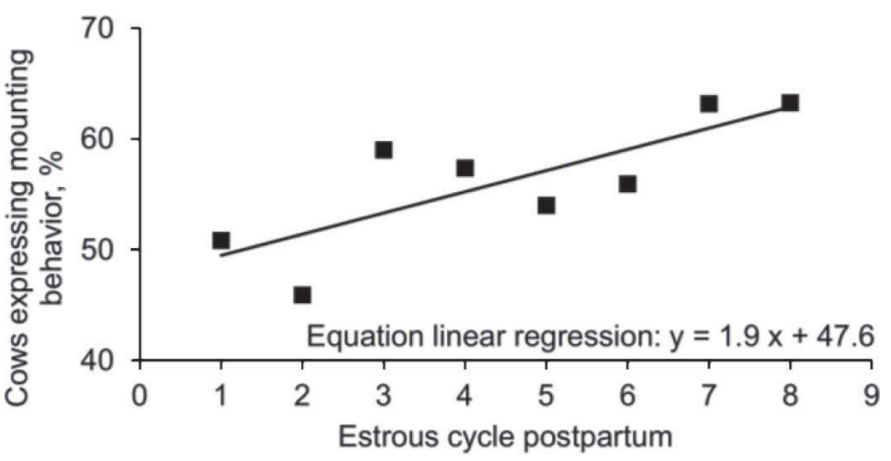

Figure 4. Percentage of cows exhibiting estrous behavior (mounting, being mounted) at each of the 8 estruses postpartum, and regression line from the correlation analysis. 


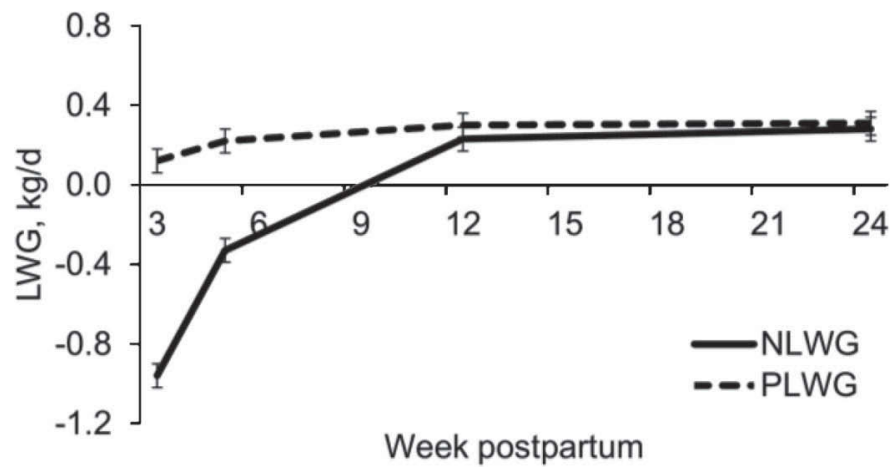

Figure 5. Live weight gain (LWG, $\mathrm{kg} / \mathrm{d}$; mean $\pm \mathrm{SEM})$ for each group (NLWG and PLWG) in wk 3, 5, 12, and 24 postpartum. PLWG $=$ cows having a positive LWG in 1 of the first 5 wk after calving; NLWG $=$ cows having a negative LWG in each of the first $5 \mathrm{wk}$ after calving.

indicating that the groups were homogenous in LW at calving. The NLWG cows lost more weight than the PLWG cows from calving to nadir (day of shift of diet for the HD-LD cows; $P=0.005)$. Moreover, from calving to first insemination, the NLWG cows lost weight whereas the PLWG gained weight $(P<0.001)$. There was no effect of feeding strategy on LWG from calving to nadir or from calving to insemination (Table 3).

IGF-1 Concentration and $L W G$. Plasma IGF-1 concentrations were different between the LWG groups at 5 wk postpartum, where the PLWG cows had higher levels of IGF- 1 than the NLWG cows (98 vs. $83 \pm 5.6$ $\mathrm{ng} / \mathrm{mL} ; P=0.05)$. Plasma IGF-1 increased for both groups from 3 to $24 \mathrm{wk}$ postpartum (Figure 6 ). The IGF-1 was higher for primiparous cows than for multiparous cows $(P<0.001)$, and was higher for the (HDLD) cows than for the (LD-LD) cows at $3 \mathrm{wk}(P=$

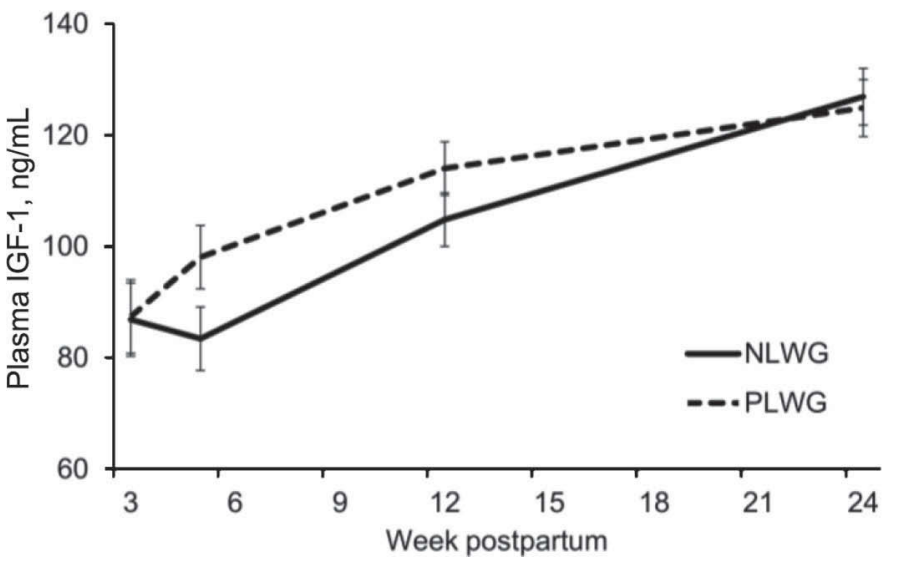

Figure 6. Plasma IGF-1 concentration (ng/mL; mean \pm SEM) for each live weight gain (LWG) group (NLWG and PLWG) in wk 3, 5 , 12 , and 24 postpartum. PLWG = cows having a positive LWG in 1 of the first 5 wk after calving; NLWG $=$ cows having a negative $L W G$ in each of the first 5 wk after calving.

$0.03)$. In addition, weekly plasma IGF-1 was positively correlated with the LWG $(\mathrm{r}=0.35, P<0.001)$.

Milk Yield and $\boldsymbol{L} W \boldsymbol{G}$. Average daily milk yield across the 4 time points studied (wk 3, 5, 12, and 24) was consistently higher for the NLWG cows than for the PLWG cows (on average 37.5 and $34.7 \pm 0.9 \mathrm{~kg}$, respectively; $P=0.03)$. There was no interaction between milk yield at the 4 time points and the LWG groups.

Estrus Intervals and $\boldsymbol{L W G}$. Interval from calving to first estrus was similar for PLWG and NLWG cows, but higher for the primiparous compared with the multiparous and higher for the HD-LD cows compared with the LD-LD cows (Table 4). The interval from calving to first estrus was higher than the following intervals $(P<0.001)$, and the interval from first

Table 3. Effects of feeding strategy and live weight gain (LWG) group on LWG, daily milk yield, DIM at first insemination, number of estrus at first insemination, number of inseminations per pregnancy, and pregnancy risks

\begin{tabular}{|c|c|c|c|c|c|c|c|c|}
\hline Item & \multicolumn{4}{|c|}{ LWG group ${ }^{1}$} & \multicolumn{4}{|c|}{ Feeding strategy $^{2}$} \\
\hline Number of cows & 29 & 33 & - & - & 31 & 31 & - & - \\
\hline Live weight at calving, $\mathrm{kg}$ & 666 & 639 & 13 & 0.13 & 647 & 656 & 13 & 0.62 \\
\hline LWG from calving to nadir ${ }^{3}$ & -34 & -15 & 5 & 0.005 & -25 & -18 & 5 & 0.25 \\
\hline LWG from calving to first insemination & -9 & 31 & 9 & $<0.001$ & 11 & 15 & 9 & 0.74 \\
\hline Number of inseminations per pregnancy & 2.59 & 2.48 & 0.25 & 0.61 & 2.35 & 2.71 & 0.25 & 0.21 \\
\hline Pregnancy risk, first insemination, $\%$ & 34.5 & 33.3 & - & 0.92 & 45.2 & 22.6 & - & 0.06 \\
\hline Pregnancy risk, second insemination, \% & 50.0 & 54.5 & - & 0.77 & 68.7 & 41.7 & - & 0.09 \\
\hline
\end{tabular}

${ }^{1} \mathrm{PLWG}=$ cows having a positive LWG in 1 of the first 5 wk after calving; NLWG: cows having a negative LWG in each of the first 5 wk after calving.

${ }^{2} \mathrm{HD}-\mathrm{LD}=$ cows fed 2 partially mixed rations, a 50:50 forage-to-concentrate diet during the mobilization period and the control diet after (60:40 forage-to-concentrate); LD-LD = cows fed the same partially mixed ration, a 60:40 forage-to-concentrate diet during all the lactation.

${ }^{3}$ Nadir: day of shift of diet for the HD-LD cows. 
to second estrus was higher than the interval between estruses 4 and 5, as well as for the following intervals $(P<0.05)$. There was no effect of LWG groups, parity, or feeding strategy on the interval from first to second estrus, this interval was, on average, $26.4 \pm 1.0 \mathrm{~d}$ for all the cows. Similarly, no effect of these factors was noted on the following intervals, which, on average, were 24.6 $\pm 0.4 \mathrm{~d}$. On average, for the interval between estrus 1 and $2,85.5 \%$ of the cows had an interval between 18 and $26 \mathrm{~d}$, and $14.5 \%$ between 31 and $57 \mathrm{~d}$. For the interval between estrus 7 and $8,96 \%$ of the cows had an interval between 18 and $26 \mathrm{~d}$, and $4 \%$ between 31 and $43 \mathrm{~d}$. The interval between estrus 7 and 8 tended to be more regular (between 18 and $26 \mathrm{~d}$ ) than the interval between estrus 1 and $2(P=0.06)$.

Reproduction and $L W G$. The frequency of mounting behavior was similar for both LWG groups $(P=$ 0.71). The feeding strategy, parity, and LWG group had no effect on the total number of inseminations per pregnancy (average 2.53 \pm 0.25 inseminations per cow). The pregnancy risk was not affected by parity group. Pregnancy risk was also similar for both LWG groups (Table 3). The pregnancy risk tended to be higher for the LD-LD cows than for the HD-LD cows (45.2 and $22.6 \%$ or 14 and 7 cows, respectively, for the first insemination, $P=0.06$; and 68.7 and $41.7 \%$ or 12 and 10 cows, respectively, for the second insemination, $P=0.09)$. The day of first insemination was similar for LWG groups $(225.5 \pm 2.6 \mathrm{~d})$ and for the 2 feeding strategies $(223.4 \pm 3.0 \mathrm{~d})$. The estrus number at first insemination was similar for the LWG groups but was higher for the LD-LD cows compared with the HD-LD cows (8.4 and $7.4 \pm 0.2$, respectively; $P=0.003$ ).

\section{DISCUSSION}

\section{Effect of Delayed Rebreeding on Production}

After calving, the EB of the cow is often negative (Butler et al., 1981) and returns to positive approximately 6 wk after calving (Gilmore et al., 2011). The several estruses occurring during an 18-mo calving interval take place in cows of different metabolic conditions, so the reduction in milk yield due to an estrus could be expected to be different at estrus 1 compared with estrus 8. Our results indicate that the first 8 estruses after calving decrease milk yield to the same extent on the day of estrus (average loss of $0.56 \pm 0.19 \mathrm{~kg}$ of milk per estrus). No other comparable results were found in the literature, as few studies have been conducted on this topic with cows on extended lactation; however, Schofield et al. (1991) found a similar decrease in milk yield at first and second estrus for cows managed for a 12-mo calving interval. In our study, the decrease

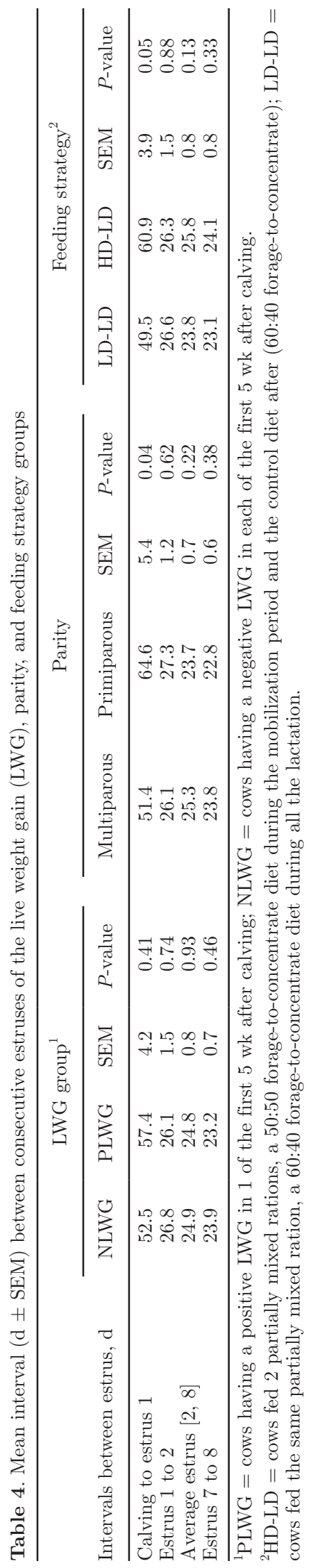


in milk yield at estrus was not due to a decrease in milking frequency. The loss of milk might be due to the fact that, during estrus, cows spend more time on activity and expressing estrus and probably also less time eating, leading to a reduction in the energy available for milk production (Hurnik et al., 1975; Kerbrat and Disenhaus, 2004). Moreover, no difference in milking frequency was observed between the day of estrus and the days preceding or following it. It has not been possible to find other studies that described variations of milking frequency around estrus with AMS and in an extended lactation setting.

\section{Effect of Estrus on Activity and Estrous Behavior}

The increase in activity during estrus is in accordance with previous studies on cows managed for a 12-mo calving interval, where the activity of the cows as well as the restlessness increased during estrus (Farris, 1954; Van Eerdenburg et al., 1996). In a more recent study, an algorithm using pedometer data was developed to identify the changes in behavior to detect estrus (Løvendahl and Chagunda, 2010). Until now the activity of cows during an extended lactation has not been studied. Our results showed a decrease in daily activity from estrus 4 to 8 . Even so, the difference in activity between day of estrus and $5 \mathrm{~d}$ before estrus is similar for all the estruses ( \pm 17 movements per hour). This can be explained by an increase of mounting behavior found with estrus number. This may indicate that, during extended lactation, the nature of the cows' activity is changing toward spending more time walking and less time mounting in early estruses, whereas the opposite is true in later estruses (Figure 7).

\section{Grouping the Cows According to Their LWG in Early Lactation}

Grouping the cows according to their LWG in early lactation was based on previous studies showing that the LWG is a good indicator of EB, and that the EB in early lactation is important for determining the onset of ovarian activity (Butler et al., 1981). In general, the more the cows are losing weight in early lactation, the greater their energy deficit, leading to a longer delay of return to estrus (Friggens, 2003). Unfortunately, a lack of knowledge exists about the importance of the effect of early lactation management on late insemination (i.e., around $8 \mathrm{mo}$ ), because most of these studies were conducted with cows managed for 12-mo calving interval; consequently, the effect of the early lactation was only tested on short-term insemination success, as this occurred around 2 mo of lactation. In our study, during the first 5 wk of lactation the NLWG cows were still be- low their calving weight at first insemination, whereas the PLWG cows were above their calving weight at their first insemination. The HD-LD cows, receiving more energy during early lactation, were expected to be over-represented in the PLWG, but the HD-LD cows were almost equally distributed between the 2 LWG groups. It seems that the LWG calculations are not accurate enough to detect small changes in energy diet. This might be due to the large daily LW variation or the small difference of energy density in the diets.

\section{Relationships Between Estrus and Other Parameters}

The NLWG cows produced more milk than the PLWG cows. As these groups were balanced according to the feeding strategy, the difference in EB between the groups suggests an individual variation and adaptation to the lactation. The NLWG cows mobilized more body tissues and for a longer time than the PLWG cows. Plasma IGF-1 level was positively correlated with LWG, and the NLWG cows had lower plasma IGF-1 than PLWG cows at $5 \mathrm{wk}$. This result is in accordance with Spicer et al. (1990), who found that serum IGF-1 concentration decreases during negative EB. Moreover, negative EB has previously been linked to reduced ovarian activity during early lactation (Butler et al., 1981; Spicer et al., 1990), and it has been shown that reproductive performance is affected by the mobilization of body energy reserves (Friggens, 2003), with thin cows being delayed in their return to estrus. In our study, the NLWG cows lost more LW than the PLWG cows until the first insemination, but the pregnancy risks between the LWG groups were similar. This last result might be due to the fact that our sample size was limited for evaluating fertility outcomes. Larger trials, such as the ones conducted by Santos et al. (2009),

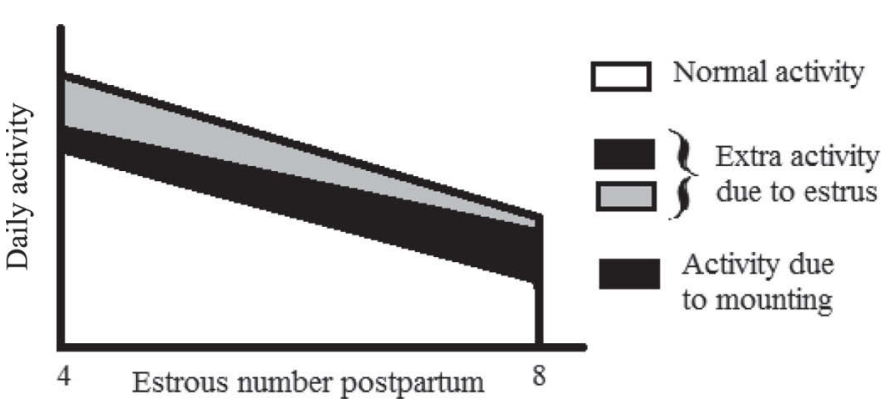

Figure 7. Diagram describing the changes in activity types and level over the estrus 4 to 8 . Daily activity is decreasing from estrus number 4 to 8 (in white), whereas mounting behavior activity is increasing (in black) during estrus. The difference of activity (in gray and black) between estrus and $5 \mathrm{~d}$ before estrus (normal activity) is the same for each estrus number postpartum. 
have shown negative effects of BCS and LW loss on return to estrus, conception rates, and pregnancy loss.

\section{Factors Influencing Pregnancy Risks}

It has been shown that the duration of the interval from calving to first estrus is related to the LW of the cow during early lactation (Haresign and Lewis, 1979); thin cows, or cows losing more weight in early lactation, need more time to return to estrus resulting in a longer interval to first estrus (Friggens, 2003). When more energy is available in early lactation, more glucose and insulin should increase the LH secretion and induce ovulation at regular intervals with stronger estrous behavior (Butler and Smith, 1989). Our results are not completely in accordance with these results; the HD-LD cows fed a more energy dense diet had the same weight loss in early lactation as the LD-LD cows and a longer interval from calving to first estrus. Regarding the LWG groups, the NLWG cows lost more weight in early lactation than the PLWG cows, but had the same interval from calving to first estrus. Moreover, a high BW loss in early lactation leads to a decrease in reproduction efficiency due to delay in insemination and lower pregnancy risks (Haresign and Lewis, 1979; Gilmore et al. 2011); but, again, our results differed from these findings, maybe due to our smaller sample size. There was no difference in pregnancy risks between our LWG groups, maybe because the difference in LWG between groups was too small and short in time to have an effect. The LD-LD cows tended to have higher pregnancy risks than the HD-LD cows. Moreover, the LD-LD cows had a shorter interval from calving to first estrus than the HD-LD cows, and, consequently, more estruses from calving to first insemination could explain the tendency for higher pregnancy risks. Indeed, it has previously been shown that an increase in the number of estrous cycles reduced the services per conception and increased the pregnancy risk at first insemination (Thatcher and Wilcox, 1973). The tendency of HD-LD cows to have lower pregnancy risks than LD-LD cows might also be due to the effect of the change to a lower energy density diet in early lactation, which prolonged mobilization and slightly decreased energy balance until the cows adapt to the new diet.

\section{CONCLUSIONS}

Milk yield decreased to $0.56 \mathrm{~kg}$ of milk on the day of estrus and was not affected by estrus number 1 to 8 in cows managed for an 18-mo calving interval. The decrease in milk yield induced by estrus was independent of milking frequency. The activity of the cow increased at the day of estrus compared with nonestrus days.
More cows expressed mounting behavior at estrus 8 compared with estrus 2. Reproductive parameters (frequency of mounting, pregnancy risk, interval to first estrus, and between-estrus intervals) were not influenced by the LW change during early lactation.

\section{ACKNOWLEDGMENTS}

The authors thank The Danish Council for Strategic Research, The Programme Commission on Health, Food and Welfare (Copenhagen, Denmark), and Aarhus University for the financial support for this experiment, and Novo Nordisk A/S (Bagsvaerd, Denmark) for supplying 1 of the 2 antibodies used in the IGF-1 assay. The staff at the Danish Cattle Research Centre (Foulum, Denmark) is acknowledged for their highly committed effort in running the experiment, as well as the team involved in the blood samples, technician Torkild Nyholm Jakobsen, and master students Jo Depandelaere and Jibon Basar. Technicians Connie Hårbo Middelhede and Martin Bjerring are acknowledged for their effective efforts in bringing about live weight and milk data, as well as Kasper Bøgild Poulsen for his efficiency and quality work on the laboratory analyses. Finally, senior researchers Peter Løvendahl and Troels Kristensen (AU Foulum, Denmark) are acknowledged for their advices on this project and for valuable comments on the manuscript.

\section{REFERENCES}

Agresti, A. 2007. An Introduction to Categorical Data Analysis. 2nd ed. John Wiley \& Sons, New York, NY.

Bossen, D., and M. R. Weisbjerg. 2009. Allocation of feed based on individual dairy cow live weight changes II: Effect on milk production. Livest. Sci. 126:273-285.

Britt, J. H., R. G. Scott, J. D. Armstrong, and M. D. Whitacre. 1986. Determinants of estrous behavior in lactating Holstein cows. J. Dairy Sci. 69:2195-2202.

Butler, W. R., R. W. Everett, and C. E. Coppock. 1981. The relationships between energy balance, milk production and ovulation in postpartum Holstein cows. J. Anim. Sci. 53:742-748.

Butler, W. R., and R. D. Smith. 1989. Interrelationships between energy balance and postpartum reproductive function in dairy cattle. J. Dairy Sci. 72:767-783.

De Silva, A. W., G. W. Anderson, F. C. Gwazdauskas, M. L. McGilliard, and J. A. Lineweaver. 1981. Interrelationships with estrous behavior and conception in dairy cattle. J. Dairy Sci. 64:24092418.

Esslemont, R. J., R. G. Glencross, M. J. Bryant, and G. S. Pope. 1980. A quantitative study of preovulatory behavior in cattle (British Friesian heifers). Appl. Anim. Ethol. 6:1-17.

Farris, E. J. 1954. Activity of dairy cows during estrus. J. Am. Vet. Med. Assoc. 125:117-120.

Foote, R. H. 1975. Estrus detection and estrus detection aids. J. Dairy Sci. 58:248-256.

Friggens, N. C. 2003. Body lipid reserves and the reproductive cycle: Towards a better understanding. Livest. Prod. Sci. 83:219-236.

Frystyk, J., B. Dinesen, and H. Orskov. 1995. Non-competitive timeresolved immunofluorometric assays for determination of human insulin-like growth factor I and II. Growth Regul. 5:169-176. 
Gilmore, H. S., F. J. Young, D. C. Patterson, A. R. G. Wylie, R. A Law, D. J. Kilpatrick, C. T. Elliott, and C. S. Mayne. 2011. An evaluation of the effect of altering nutrition and nutritional strategies in early lactation on reproductive performance and estrous behavior of high-yielding Holstein-Friesian dairy cows. J. Dairy Sci. 94:3510-3526.

Haresign, W., and D. Lewis. 1979. Body condition, milk yield and reproduction in cattle, pages 113-121 in Studies in the Agricultural and Food Sciences-Recent Advances in Animal Nutrition. Butterworth \& Co., London, UK.

Hollander, M., and D. A. Wolfe. 1973. Kendall and Spearman tests Pages 185-194 in Nonparametric Statistical Methods. John Wiley \& Sons. New York, NY.

Hurnik, J. F., G. J. King, and H. A. Robertson. 1975. Estrous and related behaviour in postpartum Holstein cows. Appl. Anim. Ethol. 2:55-68.

Kerbrat, S., and C. Disenhaus. 2004. A proposition for an updated behavioural characterisation of the estrus period in dairy cows. Appl. Anim. Behav. Sci. 87:223-238.

Laird, N. M., and J. H. Ware. 1982. Random-effects models for longitudinal data. Biometrics 38:963-974.

Lamming, G. E., and D. C. Bulman. 1976. Use of milk progesterone in diagnosis and treatment of subfertility in postpartum dairy cows. Anim. Prod. 22:140-141.

Løvendahl, P., and M. G. G. Chagunda. 2010. On the use of physical activity monitoring for estrus detection in dairy cows. J. Dairy Sci. 93:249-259.

Lucy, M. C. 2001. ADSA Foundation Scholar Award-Reproductive loss in high-producing dairy cattle: Where will it end? J. Dairy Sci. 84:1277-1293.

McArdle, C. A., and A. P. Holtore. 1989. Oxytocine and progesterone release from bovine corpus luteal cells in culture-Effects of insulin-like growth factor-I, insulin and prostaglandins. Endocrinology 124:1278-1286.

Nielsen, L. R., A. R. Pedersen, M. S. Herskin, and L. Munksgaard. 2010. Quantifying walking and standing behaviour of dairy cows using a moving average based on output from an accelerometer. Appl. Anim. Behav. Sci. 127:12-19.

Pinheiro, J., D. Bates, S. DebRoy, D. Sarkar, and R Core Team. 2015. nlme: Linear and Nonlinear Mixed Effects Models. R package version 3.1-119. Accessed Jan. 13, 2016. http://CRAN.R-project. org $/$ package $=$ nlme
Pinheiro, J. C., and D. M. Bates. 2000. Mixed-Effects Models in S and S-PLUS. Springer, New York, NY.

R Development Core Team. 2014. R: A language and environment for statistical computing. R Foundation for Statistical Computing, Vienna, Austria. Accessed Jan. 13, 2016. http://www.r-project.org Santos, J. E. P., H. M. Rutigliano, and M. F. Sa. 2009. Risk factors for resumption of postpartum estrous cycles and embryonic survival in lactating dairy cows. Anim. Reprod. Sci. 110:207-221.

Schofield, S. A., C. J. C. Phillips, and A. R. Owens. 1991. Variation in the milk production, activity rate and electrical impedance of cervical mucus over the estrous period of dairy cows. Anim. Reprod. Sci. 24:231-248.

Sorensen, A., and C. H. Knight. 2002. Endocrine profiles of cows undergoing extended lactation in relation to the control of lactation persistency. Domest. Anim. Endocrinol. 23:111-123.

Sorensen, A., D. D. Muir, and C. H. Knight. 2008. Extended lactation in dairy cows: effects of milking frequency, calving season and nutrition on lactation persistency and milk quality. J. Dairy Res. 75:90-97.

Spalding, R. W. R. W. Everett, and R. H. Foote. 1975. Fertility in New York artificially inseminated Holstein herds in dairy herd improvement. J. Dairy Sci. 58:718-723.

Spicer, L. J., W. B. Tucker, and G. D. Adams. 1990. Insulin-like growth factor-I in dairy cows-Relationships among energy balance, body condition, ovarian activity and estrous behavior. J. Dairy Sci. 73:929-937.

Steensels, M., C. Bahr, D. Berckmans, I. Halachmi, A. Antler, and E. Maltz. 2012. Lying patterns of high producing healthy dairy cows after calving in commercial herds as affected by age, environmental conditions and production. Appl. Anim. Behav. Sci. 136:88-95.

Thatcher, W. W., and C. J. Wilcox. 1973. Postpartum estrus as an indicator of reproductive status in the dairy cow. J. Dairy Sci. $56: 608-610$.

VanEerdenburg, F. J., H. S. H. Loeffler, and J. H. vanVliet. 1996. Detection of estrus in dairy cows: A new approach to an old problem. Vet. Q. 18:52-54.

Walsh, S. W., E. J. Williams, and A. C. O. Evans. 2011. A review of the causes of poor fertility in high milk producing dairy cows. Anim. Reprod. Sci. 123:127-138.

Wilmink, J. B. M. 1987. Adjustment of test day milk, fat and protein yield for age, season and stage of lactation. Livest. Prod. Sci. $16: 335-348$. 